\title{
Genetic Diversity for Root Yield and its Component Traits in Ashwagandha (Withania somnifera (L) Dunal) Pure Lines Derived from JA134 Population
}

\author{
Ponnuchamy Manivel*, Rama Reddy Nagaraja Reddy and Harshal B. Deore
}

ICAR-Directorate of Medicinal and Aromatic Plants Research, Boriavi, Anand - 387310, Gujarat, India

*Corresponding author

\author{
A B S T R A C T
}

\begin{tabular}{|c|c|}
\hline & \multirow{7}{*}{$\begin{array}{l}\text { Indian sub continent and is used in traditional systems of medicine globally. Pure lines form } \\
\text { an important genetic resource for improvement of yield and quality. In the present study, a } \\
\text { set of } 327 \text { (DWS1-DWS327) pure lines were developed from JA134 out crossed population } \\
\text { through individual plant selection, selfing and generation advancement for the first time in } \\
\text { Ashwagandha. Variation for qualitative and quantitative traits was observed between pure } \\
\text { lines and lines with distinct morphological traits were obtained. Heritability and genetic } \\
\text { divergence among a set of } 48 \text { pure lines with JA134 and JA30 was assessed based on } 20 \\
\text { root yield and its component traits. We used Mahalanobis } \mathrm{D}^{2} \text { statistics for the genetic } \\
\text { divergence estimation. The accessions were grouped in to ten clusters, where cluster I was } \\
\text { the largest containing } 12 \text { accessions, followed by cluster III consisting of ten accessions. } \\
\text { Root yield per plant (15.1\%) contributed maximum towards genetic diversity. Based on the } \\
\text { inter cluster distance and per se performance, the pure lines DWS } 84 \text { and DWS } 85 \text { were } \\
\text { selected which could be intercrossed to obtain high heterosis and also to recover } \\
\text { transgressive segregants for the improvement of root yield and its quality. Pure lines } \\
\text { developed in the present study form important genetic resources for the improvement of } \\
\text { yield and quality of Ashwagandha. }\end{array}$} \\
\hline & \\
\hline & \\
\hline $\begin{array}{l}\text { Ge } \\
\text { div } \\
\text { yie }\end{array}$ & \\
\hline Article Info & \\
\hline & \\
\hline & \\
\hline
\end{tabular}

\section{Introduction}

Herbal plants are major source of medicines for mankind since time immemorial and nearly $80 \%$ population of developing countries relies on traditional systems of medicine, mostly plant based for their primary health care. According to World Health Organization (WHO), the international market of herbal products is around $\$ 6.2$ billion, which is poised to grow to $\$ 5$ trillion by the year 2050. Among the herbal plants, Ashwagandha (Withania somnifera (L.)
Dunal) is an important medicinal plant widely used in various traditional systems of medicines like Ayurveda, Sidha, Unani, Homeopathy and others (Mir et al., 2012; Sharma et al., 2014). Ashwagandha is an erect, evergreen, perennial shrub belongs to the family Solanaceace. It is native to Indian sub-continent is also known as 'Indian Ginseng' because the roots are compared with Chinese ginseng (Panax ginseng) roots for their restorative properties (Devi, 1996). It is 
genetically diploid species $(2 \mathrm{n}=48, \mathrm{n}=24$, largely self pollinated, but some amount of cross pollination has also been reported) and suited to develop cultivars for commercial production of novel sterols and alkaloids (Singh and Kumar, 1998). Ashwagandha is a multipurpose medicinal plant, synthesizing large array of bioactive secondary metabolites in roots and leaves (Sharma and Lavil, 1981; Kandil et al., 1994). The medicinal properties of the root are attributed to Alkaloids (isopelletierine, anaferine), Steroidal lactones (withanolides, withaferins) (Srivastava et al., 1960), and saponins containing an additional acyle group (Sitoindoside VII and VIII) (Mishra et al., 2000) which are present in roots and leaves. It has important hepatoprotective, immunomodulatory, anticancer properties, anti-inflamatory, antitumor (Kumar et al., 2011 and 2012), and anti-stress, anti oxidant, mind-boosting and rejuvenating properties (Atal et al., 1975). It also increases physiological endurance and protects against stress-related disorders such as arthritis, hypertension, diabetes and premature aging (Atal et al., 1975; Chatterjee et al., 1995). Due to its wide application in pharmaceutical, cosmetic, agricultural and food industries, it has been brought under cultivation many centuries ago in India to meet its demand in national and international markets. The annual demand of ashwagandha is 7000 tonnes per annum but its actual production is 1500 tonnes per annum (Shinde et al., 2015).

Over the period of domestication and cultivation, selection of desirable plants in this species resulted in availability of annual plants which matures in 4-6 months (Misra et al., 1998; Manivel et al., 2012) otherwise it is a perennial plant. Even though it is being cultivated in India for more than two centuries, breeding efforts were initiated only few decades back and few varieties viz., JA20, JA134, JA100 from Rajmata Vijayaraje Scindia Krishi Vishwa Vidyalaya (RSVKVV),
Mandsaur, India, and Rakshita and Poshita from the CISR-Central Institute for Medicinal and Aromatic Plants (CIMAP), Lucknow, India were released for commercial cultivation (Shinde et al., 2015). All the cultivated varieties of ashwagandha were bred through repeated self-pollination of selected plants from wild or from local cultivar from farmers' field. The ashwagandha breeding efforts mainly focus on higher root yield with desirable secondary metabolites (Manivel and Reddy, 2014, Manivel, 2013). Development of pure lines in self pollinated species like ashwagandha has its own advantages, i.e. superior pure lines are used as variety for cultivation, parent in hybridization and are used to study mutations and other biological investigations such as medicine, immunology, physiology, and biochemistry. Further, the genetic diversity present among the pure lines plays a vital role in selecting the parent for hybridization.

Accurate assessment of the level and the pattern of genetic diversity is an invaluable aid in crop improvement for its diverse applications including (1) analysis of genetic variability in cultivars, (2) identifying diverse parental combinations to create segregating progenies with maximum genetic variability for further selection, and (3) introgressing desirable genes from diverse germplasm into the available genetic base (Mohammadi and Prasanna, 2003). Inbreds in crop pollinated species or pure lines in self pollinated species are the important genetic stocks for improvement, an understanding of genetic relationships among inbred lines or pure lines may be particularly useful in planning crosses, in assigning lines to specific heterotic groups, and for precise identification with respect to plant varietal protection (Hallauer and Miranda, 1988). For efficient hybridization programme, selection of genetically diverse parents and superior genotypes is pre requisite which ensures high heterosis and gamut of 
transgressive segregants for expedited development of cultivars. Multivariate analysis by means of Mahalanobis $\mathrm{D}^{2}$ statistic is a powerful tool in quantifying the degree of divergence at the genotypic level. Only few reports on the nature and extent of genetic diversity among the different morphotypes of ashwagandha based on morphometric traits were reported (Jain et al., 2007; Manivel, 2010a and Manivel, 2010b; Misra et al., 1998, Sarkar et al., 2013; Kumar et al., 2011 and 2012). However, these studies are limited to few morphometric traits and genotypes and are done using the germplasm accessions. In the present study, pure lines were developed from the JA134 population to study the genetic diversity for root yield and its component traits.

\section{Materials and Methods}

\section{Location of study}

The present investigation was carried out at the ICAR-Directorate of Medicinal and Aromatic Plants Research (ICAR-DMAPR), Boriavi, Anand, Gujarat, India. The experimental field lies in the latitude of $22.5^{\circ}$ North and longitude of $73.0^{\circ}$ East with an average rainfall of $800 \mathrm{~mm}$, minimum and maximum temperatures were between $12.7^{\circ}$ and $42^{\circ} \mathrm{C}$, respectively.

\section{Development of pure lines}

JA 134 is a commercially cultivated high yielding variety of ashwagandha released in the year 1998 from Rajmata Vijayaraje Scindia Krishi Vishwa Vidyalaya (RSVKVV), Mandsaur, Madhya Pradesh, India. Breeder seed of JA134 was obtained from them during 2002 and was multiplied in late Kharif season (Sown in August and harvested in March of next year), the bulk seeds were harvested every year and multiplied in an open field for five years. During 2006-07, in comparison to the parent variety, plants with distinct morphological variation (natural variation aroused out of natural cross pollination, natural mutation, etc.) for berry colour, leaf size and shape, plant height (shorter and taller than parent) were noticed, out of them 150 single plants were selected, tagged and selfpollinated seeds harvested individually. During 2007-08, the harvested seeds were sown in plant to row progeny, some progenies did not segregate, however some progenies showed segregations. A total of 327 individual plants were selected based on morphological traits. From 2008 to 2012, repeated selfing of individual plants from each progenies and advanced as plant-to-row progeny method for four years to develop pure lines. The scheme of development of pure lines is given in Figure 1.

\section{Evaluation of pure lines}

\section{Experimental materials}

The experimental materials for the present study consisted of 48 pure lines, JA134 (parent) and JA20, as checks. These were randomly selected from the 327 pure lines developed earlier. The checks, JA134 and JA20 were released varieties from the Rajmata Vijayaraje Scindia Krishi Vishwa Vidyalaya (RSVKVV), Mandsaur, Madhya Pradesh, India.

\section{Field evaluation}

Fourty eight-pure lines of ashwagandha along with the JA134 (parent) and JA20 (released variety) as checks were planted in a randomised complete block design (RCBD) with three replications during late Kharif season (August 2012 sowing and harvested during March of the year 2013). The pure lines were sown in a single row $(4 \mathrm{~m})$ where row to row distance was $45 \mathrm{~cm}$ and plant to plant distance was $30 \mathrm{~cm}$. Each experimental 
plot was $4 \mathrm{~m}$ long and $4 \mathrm{~m}$ wide, with 9 rows $45 \mathrm{~cm}$ apart, giving plot area of $16 \mathrm{~m}^{2}$. Adjacent block were $0.9 \mathrm{~m}$ apart. Standard good agricultural practices were followed to have optimum crop growth and development. The crop was protected from insect pests following recommended plant protection measures. Regular prophylactic measures were undertaken to prevent infestation by diseases. The crop was well-irrigated during the early growth stages to promote good crop growth.

\section{Traits studied}

The data on 20 root yield and its component traits were recorded in the pure lines. All phenotypic measurements of agronomic traits were recorded from five randomly tagged plants at the centre of the row in each replication. The traits studied includes,

\section{Plant height $(\mathrm{PH}$; in $\mathrm{cm})$ at maturity}

2. Stem height $(\mathrm{SH}$; is the height in centi meter $(\mathrm{cm})$ of main stem measured from base of the plant to the first reproductive branch at flowering)

3. Stem girth (SG; is the girth in milli meter $(\mathrm{mm})$ measured at middle of the main stem using digital vernier calipers)

4. Primary branches per plant (PB; number of primary branches on the main stem was counted at time of harvest)

5. Secondary branches per plant (SB; number of branches on primary branches was counted at time of harvest)

6. Primary branch girth (PBG; is the girth in $\mathrm{mm}$ of the longest primary branch on the main stem measured at maturity)

7. Secondary branch girth (SBG; is the girth in $\mathrm{mm}$ the longest secondary branch on primary branch measured at maturity),
8. Root length per plant (RL; is the length of the root in $\mathrm{cm}$ measured from base of the plant to the tip of the root at the time of harvest)

9. Root girth at top portion (RGT; root girth in $\mathrm{mm}$ was measured at the top (base) portion of the primary root at the time of harvest)

10. Root girth at middle portion (RGM; root girth in $\mathrm{mm}$ at the middle portion of the primary root at the time of harvest)

11. Root girth at bottom portion (RGB; root girth in $\mathrm{mm}$ measured at the tip of primary root at the time of harvest)

12. Secondary roots per plant (SR; is the number of secondary roots counted at the time of harvest)

13. Secondary root length (SRL; length of the longest secondary root in centi meter $(\mathrm{cm})$ measured at the time of harvest)

14. Secondary root girth (SRG; is the girth of the secondary root in mm measured using digital vernier calipers at the time of harvest)

15. Number of berries per plant (NB)

16. Number of leaves per plant (NL)

17. Leaf yield per plant (LY; g)

18. Stem yield per plant (STY; cm)

19. Root yield per plant (RY; g) and

20. Seed yield per plant (SY; g)

\section{Statistical analysis}

Trait variances were partitioned using the random effects analysis of variance (ANOVA) model $y=\mu+G+$ error, where $G$ represents genotype. The error term includes the variance 
between means for the three replicates of each genotype. We used Proc GLM procedure of Satistical analysis software (SAS) with replication mean data of each trait in a year for studying the effect of genotype (pure lines) for observed variance by residual maximum likelihood algorithm (REML) as suggested by Patterson and Thompson (1971).

Broad-sense heritabilities were estimated using SAS code for estimating heritability from lines evaluated in RCB designs (Holland et al., 2003), modified to account for repeated measurements on perennial plants over years substituted for environments. The basic SAS code for estimating heritabilities and genotypic correlations is available at http://www4.ncsu.edu/ jholland/heritability.ht $\mathrm{ml}$ (verified on $20 \mathrm{Dec}, 2014$ ) and also available with authors. Mahalanobis $\mathrm{D}^{2}$ statistics (Mahalanobis, 1936) and Toucher's method as described by (Rao, 1952) were used for determining group constellations. Average intra and inter cluster distances were estimated as per the procedure outlined by Singh and Chaudhary (1977). SAS computer program (SAS, 2009) was employed for the statistical analysis.

\section{Results and Discussion}

\section{Development of Pure lines}

A total of 327 pure lines of ashwagandha were developed from a JA134 out crossed population by individual plant selection, selfing and generation advancement during 2008 to 2012. These pure lines (DWS1 to DWS327) breed true to type, uniform and morphologically distinct from each other. Some of the morphologically distinct pure lines are given in Table 1. As expected the pure lines showed variation for quantitative traits thus providing an opportunity to study the genetic diversity for these traits.

\section{Trait performance}

The analysis of variance revealed significant differences among the pure lines for all the traits studied (Table S1). High (more than $60 \%$ ) genotypic coefficient of variation (GCV) and phenotypic co-efficient of variation (PCV) was observed for secondary root girth (SRG; 60.40 and 73.60, respectively), leaf yield (LY; 69.10 and 75.20, respectively), stem yield (STY; 65.50 and 71.90, respectively), root yield (RY; 74.10 and 79.60, respectively) and seed yield (SY; 70.76 and 79.50, respectively) (Table 2) indicating presence of genetic variability in the pure lines. The broad-sense heritability $\left(\mathrm{h}^{2}\right)$ values were high and ranged from 74 to 93 per cent (Table 2). Secondary roots (SR) showed the lowest heritability $\left(\mathrm{h}^{2}=60.00\right)$ among the traits, indicating more influence of environment in the expression of trait. The genetic advance over mean ranged from 9.95 to 150.93 . The histograms of trait distribution showed normality suggesting quantitative inheritance (Supplementary Figure 1.) for all the traits.

\section{Genetic divergence}

Based on $\mathrm{D}^{2}$ statistics and Tocher's clustering method the 50 genotypes (48 pure lines and 2 checks) were grouped into 10 clusters with the variable number of entries in each cluster (Table 3 and Figure 2). This indicated the broad genetic diversity among the pure lines obtained from JA134 population. Cluster I had the maximum number (12) of genotypes followed by cluster III with ten and cluster V with seven accessions. Further, cluster IX and $\mathrm{X}$ remained solitary clusters. The checks JA134 and JA20 were included in clusters III and VII, respectively indicating their distinctness or similarity with the pure lines. Out of 48 pure lines, 9 were grouped in cluster III where its parent variety JA 134 is placed and remaining pure lines were grouped in different cluster. 
Average intra and inter cluster $\mathrm{D}^{2}$ values among 48 accessions and two checks (Table 4) revealed that cluster III had the minimum intra cluster distance (3.20) indicating the accessions within this cluster were similar. While, the clusters IX and $X$ showed maximum intra cluster $\mathrm{D}^{2}$ value (7.80 each), followed by cluster II (6.40) and cluster VIII (6.40) revealing there by the existence of diverse accessions that fell into these clusters. The inter cluster $\mathrm{D}^{2}$ values ranged from 11.90 to 273.80 and the minimum inter cluster $\mathrm{D}^{2}$ values were observed between cluster $\mathrm{V}$ and VI (11.30) and cluster III and V (13.70) indicating close relationship among the accessions included in these clusters. Maximum inter cluster distance was observed between clusters IX and X (273.80) and clusters VII and X (198.40) which indicates that genotypes included in these clusters are more diverse. Crosses between genotypes of these clusters may give wide variation in the segregating populations.

The cluster means and contribution of each trait towards genetic divergence were presented in the Table 5. The percent contribution towards genetic diversity was highest for root yield per plant $(15.1 \%)$ followed by seed yield per plant (12.0\%) and the least contribution from root girth at the top, root girth at the bottom and length of secondary root. The results revealed considerable differences among the clusters for most of the traits studied. The solitary cluster X (DWS84) recorded the highest for plant height $(68.1 \mathrm{~cm})$, stem height $(32.5 \mathrm{~cm})$, stem girth $(7.4 \mathrm{~mm})$, number of secondary branches (24.2), root girth at top $(37.8 \mathrm{~mm})$, root girth at middle $(29.3 \mathrm{~mm})$, secondary root length $(18.4 \mathrm{~cm})$, total number of berries (1950) and the number of leaves (757), primary braches length $(25.2 \mathrm{~cm})$, and secondary branch length $(40.3 \mathrm{~cm})$ whereas other solitary cluster IX recorded highest for root branch number (12.0), leaf yield per plant $(67.1 \mathrm{~g})$, stem yield per plant $(127.3 \mathrm{~g})$ and root yield per plant $(29.6 \mathrm{~g})$. The cluster IV (DWS225, DWS222, DWS220, DWS195 and DWS70) recorded the highest root node girth $(4.5 \mathrm{~mm})$ and seed weight per plant (56.3 g).

Ashwagandha is an important medicinal plant where root, stem and leaves are the economic parts used in various indigenous systems of medicine in India and across the world. Concerted breeding efforts are needed to meet the growing market demand. Enhancing the root yield and its quality are the important breeding objectives of ashwagandha. Because ashwagandha is a self pollinated species, pure line breeding is used for its quick improvement. In the present study, 327 pure lines of ashwagandha were developed from a JA134 population by individual plant selection, selfing and generation advancement from 2008 to 2012 for the first time. These pure lines breed true to type, uniform and morphologically distinct (Figure 2.) from each other.

The high root yielding pure lines with desirable traits can be released as a new variety for cultivation and the other pure lines with desirable qualitative and quantative traits can be used as parents for genetic studies and further improvement using appropriate breeding methods. Lattoo et al., (2007) also reported natural out crossing in ashwagandha variety 'poshita' leading to creation of genetic variability of Ashwagandha. In ashwagandha, the Pureli DWS327 was registered for its dwarf plant type $(<30 \mathrm{~cm})$ with high 'withanolide A'content $(>1.75 \mathrm{mg}$ per gram dry weight) by the National Bureau of Plant Genetic Resources (NBPGR) New Delhi (INGR 11026: IC0588697) as useful germplasm for utilization in the ashwagandha breeding programme (Manivel et al., 2012) and a new growth habit i.e. procumbent plant (DWS6) was also registered with INGR 13047- (IC0590838) (Manivel et al., 2013). These pure lines form on important resource for genetic analysis of various morphological 
traits (Deore and Manivel 2014) besides genetic improvement of yield and quality traits.

The nature and magnitude of genetic variability available in the pure lines has significant role in the development of improved varieties. Further, assessment of heritable and non heritable components of genetic variability is of immense value in the choice of methods of improvement. High heritability was observed for root yield and its component traits indicating greater genetic variance in the pure lines for the characters under study. Heritability estimates along with the genetic advance are helpful in predicting the gain from the selection than heritability estimate alone (Johnson et al., 1955). High heritability coupled with high genetic advance over mean was recorded for number of berries, number of leaves, leaf yield, stem yield and seed yield indicating greater scope for improvement of these traits through direct selection. Yadav et al., (2008) observed high heritability coupled with high genetic advance over mean for number of berries per plant and other traits in ashwagandha. High heritability with low genetic advance was noticed for stem height, stem girth, primary branches, secondary branches, secondary branch height, primary root length, secondary roots, root girth at top, root girth in the middle, root girth at bottom, secondary root girth, and secondary root length in the pure lines studied indicating the influence of environment in the expression of these characters. Therefore, direct selection for improvement of these traits may not be effective.

The Mahalanobis $\mathrm{D}^{2}$ statistics is a powerful tool to measure the genetic divergence within a set of genotypes (Murthy and Arunachalam, 1966). An insight into genetic diversity present in the pure lines provides a greater scope for exploiting them and forms an invaluable aid for improvement of yield and quality of ashwagandha. The genetic divergence among a set of 48 pure lines was assessed using Mahalanobis $\mathrm{D}^{2}$ statistics. The genotypes were grouped into 10 clusters, however, with the variable number of entries in each cluster revealing considerable amount of genetic diversity among the genotypes indicating diversity among the pure lines. Diversity in the pure lines observed in the bulk population of JA 134 might have arisen due to natural mutations, variation due out crossing and natural selection. Earlier Jain et al., (2007) grouped 21 morphotypes into five groups based on 11 morphometric characters in ashwagandha. Similarly, Kumar et al., (2012) grouped 21 genotypes in to five clusters based on 12 traits. Grouping of genotypes based on $\mathrm{D}^{2}$ statistics of practical value to the breeders as it facilitates the selection of genotypes. In breeding program, generally parents are selected based on the genetic divergence for obtaining transagressive segregants and superior genotypes. Among the 20 traits studied, the root yield per plant and seed yield per plant contributed maximum towards divergence. In the present study, the inter cluster differences and per se performance of the accessions were used to select genetically diverse and agronomically superior genotypes. Maximum inter cluster distance was observed between clusters IX and X (273.80) and clusters VII and X (198.40) which indicates that genotypes included in these clusters are more diverse. The genotypes exceptionally superior with respect to one or more traits were deemed desirable. On this basis, DWS84 and DWS85 were distinct and diverse may be selected as promising lines for the improvement of root yield. Intercrossing of diverse groups would lead to broad genetic base and greater opportunities for recombination to occur which intern may unlock hidden variability by breaking undesirable linkages (Thoday, 1980). Moreover, selection of parents from each cluster and crossing them in a series of diallel 
crosses were proved to be highly fruitful. The progenies from such diverse crosses are expected to show wide variability, providing greater scope for isolating transgressive segregants in the advanced generations. Hence, these pure lines may be used repeatedly in the hybridization program to develop elite lines which either can be released as a variety or can be utilized in the genetic enhancement. The genetic diversity among pure lines in comparison with its parental variety revealed that the pure lines developed were genetically divergent from their parents.
In conclusion, pure lines forms an important genetic resource for the genetic enhancement of yield and quality of Ashwagandha, a self pollinated crop with immense medicinal importance. For the first time, 327 pure lines with distinct, uniform and stable morphological characters were developed from JA134 bulk population. Genetic diversity analysis in a set of 48 pure lines was shown that the pure lines are diverse. Maximum contribution towards genetic diversity was observed with root yield per plant (RL; 15.1\%).

Table.1 Distinct morphological characters of some of the pure lines developed from JA134 population

\begin{tabular}{|l|l|l|}
\hline No. & Name & Distinct morphological Character(s) \\
\hline 1 & DWS327 & Dwarf plant $(<30 \mathrm{~cm})$ \\
\hline 2 & DWS6 & Procumbent type plant \\
\hline 3 & DWS10 & Male sterile plant \\
\hline 4 & DWS12 & Straight margin/non-wavy margin \\
\hline 5 & DWS16 & Yellowish colour leaf \\
\hline 6 & DWS23 & Compact pant with less fibrous root \\
\hline 7 & DWS37 & Downward curling leaves \\
\hline 8 & DWS61 & Triangular shape leaves \\
\hline 9 & DWS65 & Creamy colour berry \\
\hline 10 & DWS69 & Non-wavy and elongated leaves \\
\hline 11 & DWS110 & Broad leaves \\
\hline 12 & DWS112 & Big size flowers \\
\hline 13 & DWS114 & More hairs \\
\hline 14 & DWS117 & Open calyx/berries visible \\
\hline 15 & DWS127 & Yellow colour young leaves \\
\hline 16 & DWS131 & Red berry, non wavy leaves, tall and leaf margin entire \\
\hline 17 & DWS144 & Yellow green leaves \\
\hline 18 & DWS139 & Branches on every node \\
\hline 19 & DWS195 & More wavy leaves \\
\hline 20 & DWS207 & Profuse branches \\
\hline 21 & DWS217 & Spreading type (Procumbent) \\
\hline 22 & DWS260 & More hairs on stem and leaves \\
\hline 23 & DWS268 & Long leaves \\
\hline 24 & DWS135 & Orange colour berries \\
\hline
\end{tabular}


Table. 2 Heritability and Genetic advance for 20 root yield and its component traits in ashwagandha pure lines

\begin{tabular}{|l|l|l|l|l|l|l|}
\hline Traits & Mean & $\begin{array}{l}\text { PCV } \\
(\boldsymbol{\%})\end{array}$ & $\begin{array}{l}\text { GCV } \\
(\boldsymbol{\%})\end{array}$ & $\begin{array}{l}\mathbf{h}^{2} \\
(\boldsymbol{\%})\end{array}$ & $\begin{array}{l}\text { Genetic } \\
\text { advance }\end{array}$ & $\begin{array}{l}\text { GAM } \\
(\boldsymbol{\%})\end{array}$ \\
\hline Plant height (PH in cm) & 45.20 & 23.00 & 20.40 & 89.00 & 18.60 & 41.15 \\
\hline Stem height (SH in cm) & 20.60 & 25.60 & 22.30 & 87.00 & 9.50 & 46.12 \\
\hline Stem girth (SG in mm) & 5.90 & 30.80 & 25.60 & 83.00 & 3.00 & 50.85 \\
\hline Primary branches (PB) & 5.80 & 43.40 & 37.80 & 87.00 & 4.60 & 79.31 \\
\hline Secondary branches (SB) & 13.60 & 30.90 & 25.90 & 84.00 & 7.20 & 52.94 \\
\hline Primary branch length (PBL) (cm) & 21.90 & 36.40 & 32.80 & 90.00 & 14.00 & 63.93 \\
\hline Secondary branch length (SBL) (cm) & 14.60 & 29.90 & 22.20 & 74.00 & 6.30 & 43.15 \\
\hline Primary root length (PRL) (cm) & 15.60 & 33.50 & 26.10 & 78.00 & 8.30 & 53.21 \\
\hline Secondary roots (SR) & 6.10 & 80.70 & 48.40 & 60.00 & 6.20 & 101.64 \\
\hline Root girth at top (RGT in mm) & 14.60 & 23.90 & 19.10 & 80.00 & 5.60 & 38.36 \\
\hline Root girth in the middle (RGM in mm) & 9.80 & 27.20 & 23.10 & 85.00 & 4.50 & 45.92 \\
\hline Root girth at bottom (RGB in mm) & 4.90 & 36.80 & 30.60 & 83.00 & 3.00 & 61.22 \\
\hline Secondary root girth (SRG in mm) & 2.30 & 73.60 & 60.40 & 82.00 & 2.80 & 121.74 \\
\hline Secondary root length (SRL in cm) & 7.70 & 49.20 & 36.90 & 75.00 & 5.60 & 72.73 \\
\hline Number of berries (NB) & 614.90 & 59.40 & 51.10 & 86.00 & 62.50 & 10.16 \\
\hline Number of leaves (NL) & 274.40 & 55.80 & 48.00 & 86.00 & 27.30 & 9.95 \\
\hline Leaf yield (LY) (g) & 19.70 & 75.20 & 69.10 & 92.00 & 28.70 & 145.69 \\
\hline Stem yield (STY) (g) & 33.80 & 71.90 & 65.50 & 91.00 & 44.50 & 131.66 \\
\hline Root yield (RY) (g) & 10.80 & 79.60 & 74.10 & 93.00 & 16.30 & 150.93 \\
\hline Seed yield (SY) (g) & 29.40 & 79.50 & 70.80 & 89.00 & 42.80 & 145.58 \\
\hline
\end{tabular}


Table.3 Clustering pattern of ashwagandha pure lines on the basis of 20 root yield and its component traits

\begin{tabular}{|l|l|l|}
\hline Cluster & $\begin{array}{l}\text { Number of } \\
\text { accessions }\end{array}$ & Pure lines \\
\hline I & 12 & $\begin{array}{l}\text { DWS88, DWS133, DWS8, DWS51, DWS134, DWS132, } \\
\text { DWS13, DWS105, DWS62, DWS3, DWS4, DWS9 }\end{array}$ \\
\hline II & 2 & DWS106, DWS114 \\
\hline III & 10 & $\begin{array}{l}\text { DWS80, DWS228, DWS57, DWS50, DWS1, DWS94, DWS 89, } \\
\text { DWS83, JA134, DWS95 }\end{array}$ \\
\hline IV & 5 & DWS225, DWS222, DWS220, DWS195, DWS70 \\
\hline V & 7 & DWS92, DWS224, DWS96, DWS141, DWS63, DWS97, DWS86 \\
\hline VI & 5 & DWS142, DWS143, DWS87, DWS20, DWS93 \\
\hline VII & 5 & DWS196, DWS197, DWS48, JA20, DWS98 \\
\hline VIII & 2 & DWS7, DWS131 \\
\hline IX & 1 & DWS85 \\
\hline X & 1 & DWS84 \\
\hline
\end{tabular}

Table.4 Intra cluster (bolded diagonal) and inter cluster (off diagonal) distance $\left(\mathrm{D}^{2}\right)$ values among ashwagandha pure lines based on 20 root yield and its component traits

\begin{tabular}{|l|l|l|l|l|l|l|l|l|l|l|}
\hline Cluster & I & II & III & IV & V & VI & VII & VIII & IX & X \\
\hline I & $\mathbf{2 . 9 0}$ & 25.7 & 17.60 & 22.00 & 16.30 & 18.10 & 34.30 & 15.00 & 81.90 & 143.80 \\
\hline II & & $\mathbf{6 . 4}$ & 25.70 & 23.20 & 24.50 & 21.20 & 37.70 & 36.80 & 79.10 & 156.00 \\
\hline III & & & $\mathbf{3 . 2 0}$ & 18.90 & 13.70 & 22.00 & 17.40 & 23.30 & 95.00 & 189.30 \\
\hline IV & & & & $\mathbf{4 . 6 0}$ & 21.80 & 19.30 & 26.00 & 31.30 & 101.40 & 170.20 \\
\hline V & & & & & $\mathbf{3 . 9 0}$ & 11.90 & 23.70 & 24.40 & 89.60 & 157.90 \\
\hline VI & & & & & & $\mathbf{4 . 6 0}$ & 31.60 & 28.50 & 92.10 & 157.80 \\
\hline VII & & & & & & & $\mathbf{4 . 6 0}$ & 23.10 & 128.80 & 198.40 \\
\hline VIII & & & & & & & & $\mathbf{6 . 4 0}$ & 103.20 & 166.80 \\
\hline IX & & & & & & & & & $\mathbf{7 . 8 0}$ & 273.80 \\
\hline X & & & & & & & & & & $\mathbf{7 . 8 0}$ \\
\hline
\end{tabular}

$\mathrm{n}_{2}=25$ and 30.55 at $5 \%$ and $1 \%$ probability level, respectively 
Table.5 Cluster mean values for 20 root yield and its component traits in ashwagandha pure lines

\begin{tabular}{|c|c|c|c|c|c|c|c|c|c|c|c|c|c|c|c|c|c|c|c|c|}
\hline Clusters & PH & $\mathrm{SH}$ & SG & PB & SB & PBL & SBL & $\mathbf{R L}$ & RGT & RGM & RGB & SR & SRL & SRG & NB & NL & LY & STY & RY & SY \\
\hline $\mathrm{I}$ & 39.0 & 19.1 & 5.2 & 5.2 & 11.3 & 23.2 & 14.6 & 15.9 & 12.4 & 7.6 & 4.1 & 7.5 & 7.0 & 1.4 & 294.1 & 140.1 & 10.6 & 17.4 & 12.7 & 24.5 \\
\hline II & 47.0 & 26.0 & 6.6 & 5.2 & 14.7 & 22.5 & 13.6 & 16.5 & 18.6 & 12.7 & 4.1 & 4.0 & 6.4 & 1.3 & 1390.8 & 386.2 & 23.9 & 32.0 & 8.0 & 49.9 \\
\hline III & 50.2 & 19.0 & 6.8 & 7.6 & 15.1 & 24.6 & 16.0 & 14.8 & 14.3 & 9.6 & 4.9 & 6.8 & 8.9 & 2.5 & 384.5 & 304.2 & 19.0 & 37.3 & 11.3 & 21.4 \\
\hline IV & 49.0 & 21.8 & 6.8 & 7.0 & 14.0 & 20.1 & 15.4 & 17.0 & 15.9 & 10.2 & 5.6 & 4.8 & 6.1 & 4.5 & 1123.4 & 212.1 & 19.0 & 47.0 & 8.2 & 56.3 \\
\hline $\mathrm{V}$ & 42.9 & 21.8 & 5.7 & 4.8 & 12.6 & 18.6 & 13.1 & 16.9 & 14.5 & 10.0 & 4.9 & 5.2 & 7.1 & 2.6 & 590.0 & 367.9 & 20.5 & 37.0 & 10.5 & 18.4 \\
\hline VI & 44.7 & 21.6 & 4.4 & 5.1 & 13.7 & 20.6 & 13.5 & 13.3 & 14.4 & 10.1 & 5.3 & 4.7 & 6.7 & 2.3 & 831.1 & 402.5 & 35.8 & 34.4 & 8.4 & 16.3 \\
\hline VII & 49.6 & 20.9 & 6.6 & 5.7 & 15.0 & 23.2 & 13.2 & 14.9 & 15.1 & 10.9 & 7.3 & 5.7 & 9.6 & 2.5 & 665.4 & 210.0 & 16.2 & 36.0 & 11.4 & 47.4 \\
\hline VIII & 29.9 & 18.6 & 3.0 & 4.1 & 7.7 & 15.9 & 8.6 & 18.2 & 7.3 & 4.2 & 2.0 & 3.9 & 4.6 & 2.0 & 111.2 & 40.3 & 4.4 & 7.7 & 3.2 & 25.9 \\
\hline IX & 47.8 & 13.8 & 6.7 & 5.1 & 22.9 & 21.4 & 7.8 & 11.9 & 18.1 & 12.9 & 4.5 & 12.0 & 8.8 & 0.4 & 1190.9 & 689.5 & 67.1 & 127.3 & 29.6 & 38.2 \\
\hline $\mathrm{X}$ & 68.1 & 32.5 & 7.4 & 4.8 & 24.2 & 25.2 & 40.3 & 15.0 & 37.8 & 29.3 & 5.0 & 9.0 & 18.4 & 2.7 & 1950.0 & 757.4 & 46.8 & 57.4 & 8.2 & 43.4 \\
\hline $\begin{array}{l}\text { Per cent } \\
\text { Contribution } \\
\text { to the } \\
\text { divergence }\end{array}$ & 6.5 & 2.0 & 5.0 & 10.4 & 6.6 & 0.6 & 2.0 & 6.0 & 0.0 & 0.1 & 1.0 & 3.0 & 0.0 & 0.5 & 4.5 & 8.2 & 9.5 & 7.0 & 15.1 & 12.0 \\
\hline
\end{tabular}

Plant height (PH), Stem height (SH), Stem girth (SG), Primary branches (PB), Secondary branches (SB), Primary Branch length (PBL), Secondary branch length (SBL), Primary root length (RL), Root girth at top (RGT), Root girth in the middle (RGM), Root girth at bottom (RGB), Secondary roots (SR), Secondary root length (SRL), Secondary root girth (SRG), Number of berries (NB), Number of leaves (NL), Leaf yield (LY), Stem yield (STY), Root yield (RY), Seed yield (SY) 
Fig.1 Scheme of pure line development to study the genetic diversity in Ashwagandha

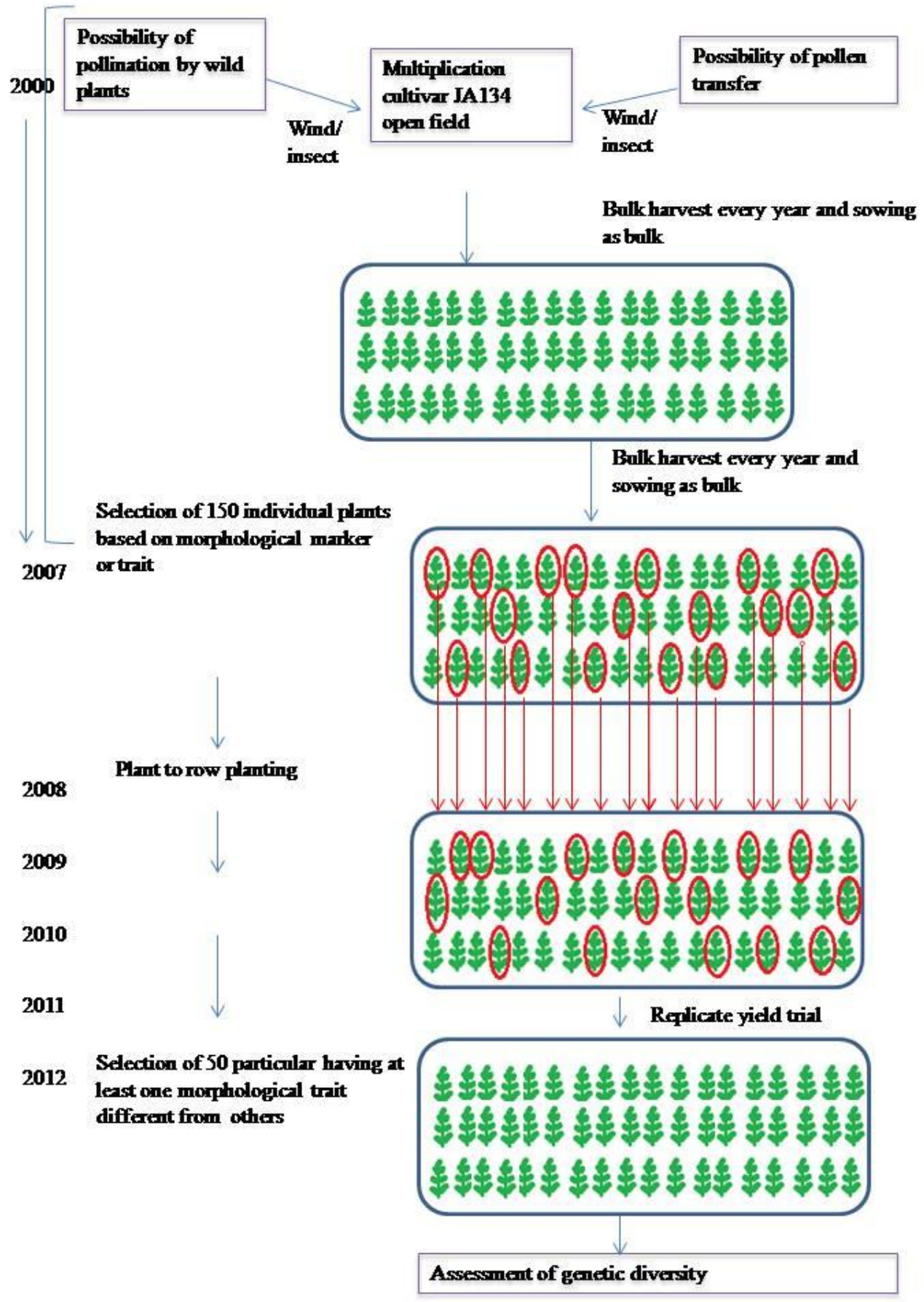


Fig.2 Ashwagandha pure line DWS37 (Downward curling leaves), DWS144 (Yellow green leaves), DWS127 (yellow young leaves), DWS65 (Creamy colour berry), DWS131(Red berry), DWS135 (Orange) and JA134 (Green leaves with yellow berries)

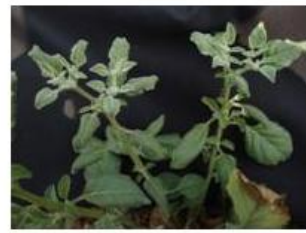

DW537

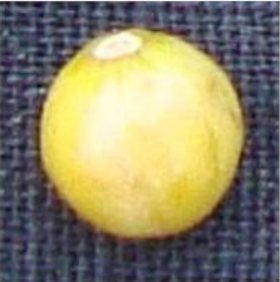

DW565

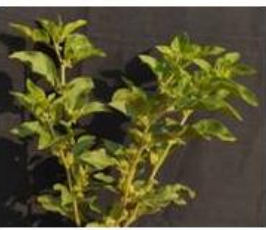

DWS144

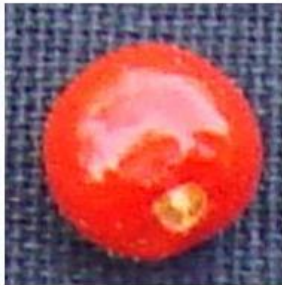

DWS131

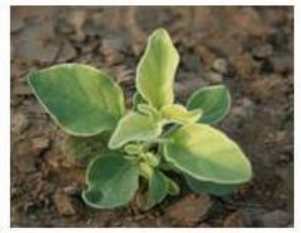

Dus 27

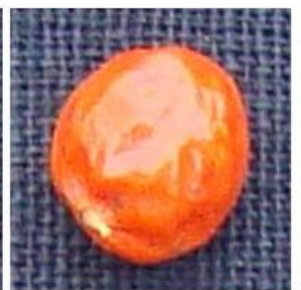

DWS135

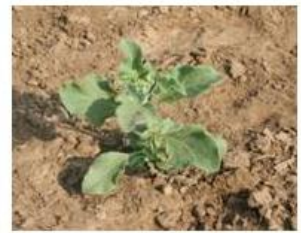

IA 34(parent)

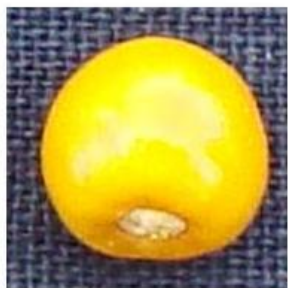

IA134 (Parent)

Fig.3 Dendogram constructed using UPGMA method depicting the clustering of ashwagandha pure lines based on 20 root yield and its component traits; The scale at the bottom Jaccard's similarly coefficient

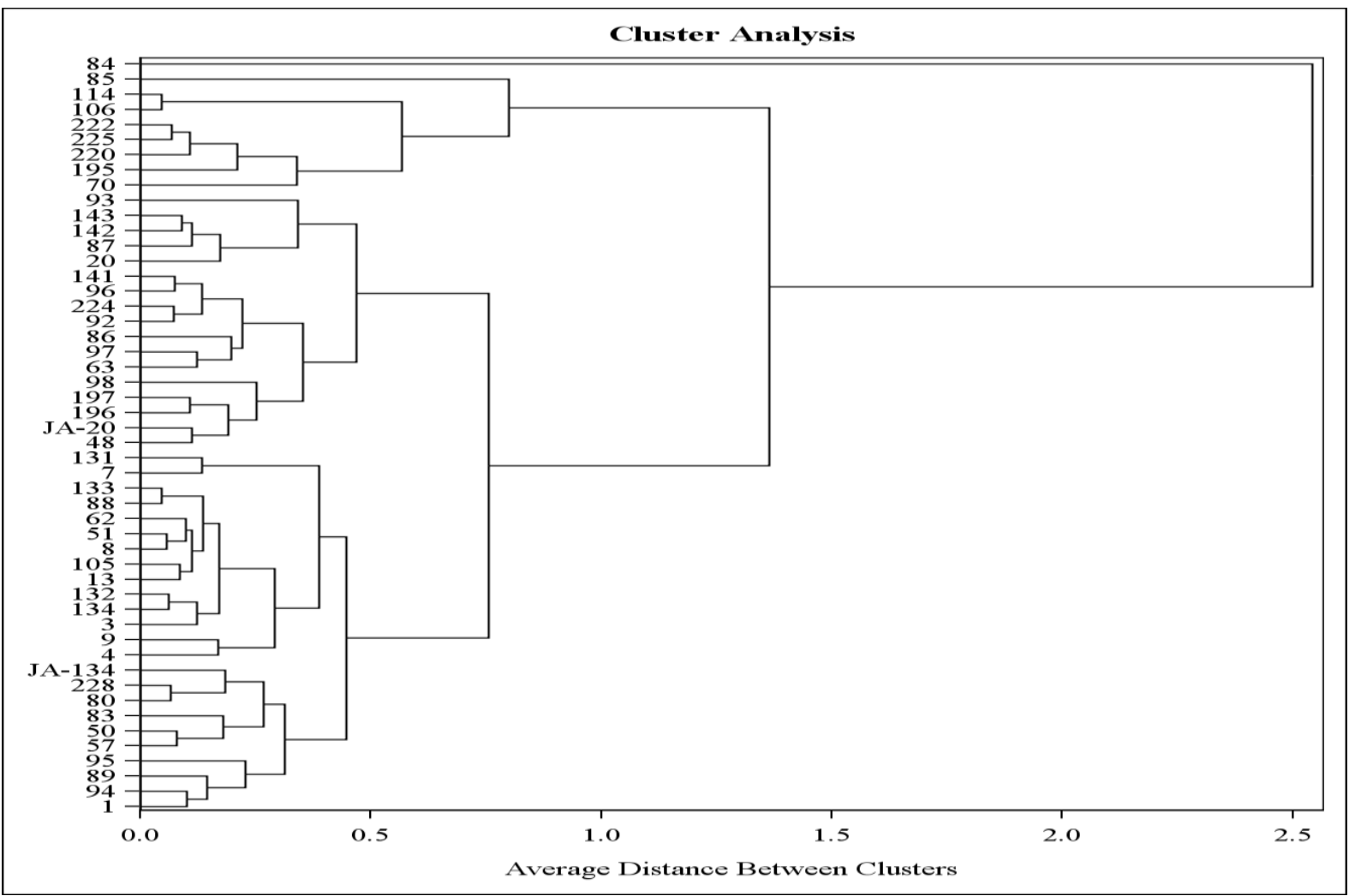


Based on the inter cluster distance and per se performance, the pure lines DWS84 and DWS85 may be selected which could be intercrossed to obtain high heterosis and also to recover transgressive segregants for the improvement of root yield and its quality. Pure lines with distinct morphological characters with desired yield and quality would be released as cultivars and others may be useful for genetic studies.

\section{Acknowledgements}

The authors gratefully acknowledge the Director, ICAR-Directorate of Medicinal and Aromatic Plants Research (DMAPR), Anand, Gujarat, India and Indian Council of Agricultural Research (ICAR), New Delhi for the facilities to undertake the study and Dr. N. Manivannan, Professor (Oilseeds), TNAU, Coimbatore for his critical comments on the manuscript for its improvement.

\section{References}

Atal, C.K., Gupta, O.P., Raghunathan, K., Dhar, K.L. $\quad 1975 . \quad$ Pharmacognosy and phytochemistry of Withania somnifera (L.) Dunal (Ashwagandha). Central Council for Research in Indian Medicine and Homeopathy, New Delhi.

Chatterjee, S.C. 1995. The Treatise on Indian Medicinal Plants Publications \& Information Directorate $4^{\text {th }}$ Edn.

Devi, P.U. 1996. Ashwagandha: Potential plant source of a promising drug for cancer chemotherapy. Indian J. Exp. Biol., 34(10): 927- 932 .

Deore, H.B., Manivel, P. 2014. Inheritance of growth habit and berry colour in ashwagandha (Withania somnifera (L.) Dunal)-A medicinal plant. E. J. Plant Breeding, 5(2):244-247.

Hallauer, A.R., Miranda, J.B. 1988. Quantitative genetics in maize breeding. $2^{\text {nd }}$ edition, Iowa State University Press, Ames, I.A.

Holland, J.B., Nyquist, W.E., Cervantes-Martinez, C.T. 2003. Estimating and interpreting heritability for plant breeding: An update.
Plant Breed Rev., 22: 9-112. John Wiley \& Sons, New York.

Jain, S.K., Bordia, P.C., Joshi, A. 2007. Genetic diversity in Ashwagandha. J. Med. Aromatic Plant Sci. 29, 11-15.

Johanson, H., Robinson, H.F., Comstock, R.E. 1955. Estimates of genetic and environmental variability in soyabean. Agronomy J., 47: 314-318.

Kandil, F.E., Elsayeh, N.H., Abou-Douh, A.M., Ishak, M.S., Mabry, T.J. 1994. Flavonol glycosides and Phenolics from Withania somnifera. Phytochem., 37: 215-1216.

Kumar, R.R., Reddy, L.P.A., Niranjana, A., Kumar, A., Komaraih, K., Puranand, S., Sastry, K.P. 2011. Root textural quality in ashwagandha (Withania somnifera) as influenced by crop growth periods and morphotypes. Ind. Crops Prod., 34: 12311234.

Kumar, R.R., Reddy, L.P.A., Niranjana, A., Kumar, A., Komaraih, K., Puranand, S., Sastry, K.P. 2012. Multivariate analysis and genetic diversity for morphometric and root textural quality traits in ashwagandha (Withania somnifera (L.) Dunal). Ind. Crops Prod., 35(1): 199-202

Lattoo, S.K., Dhar, R.S., Khan, S., Bamotra, S., Dhar, A.K. 2007. Temporal sexual maturation and incremental staminal movement encourages mixed mating in Withania somnifera-an insurance for reproductive success. Curr. Sci., 92: 13901399.

Mahalanbolis, P.C. 1936. On the generalized distance in statistics; Proc. Nat. Instit. Sci., 2: 49-55.

Manivel, P. 2010a. Status of genetic diversity in Ashwagandha (Withania somnifera): an important medicinal plant. In: $3^{\text {rd }}$ National conference on Plant Breeding and Genomics, 7-9 July, 2010.Tamil Nadu Agricultural University, Coimbatore. Pp. 18-20.

Manivel, P. 2010b. Breeding medicinal plants in India: Current scenario and future opportunities. In: Proceedings of the $3^{\text {rd }}$ Indo-Korean joint seminar on Medicinal Plant Research, 23 ${ }^{\text {rd }}$ February, 2010. Avinnashilingam University for Women, Coimbatore. Pp. 25-44. 
Manivel, P., Kumar, V., Gajbhiye, N.A., Maiti, S. 2012. DWS 327 - A dwarf pure line of Ashwagandha [Withania somnifera (L.) Dunal]. Indian J. Genet. Plant Breed., 72(4): 489.

Manivel, P., Reddy, N.R. 2014. Biodiversity conservation of Medicinal Plants in India "In: NABS "National Seminar on "Biodiversity conservation, status, future and way forward., July, 19-20 2014 at K.S. Rangasway college of Technology, Thiruchengode, Tamilnadu, India. Pp.525540.

Manivel, P., Gajbhiye, N.A., Maiti, S. 2013. DWS-6 (IC0590838; INGR13047) a new plant type of Ashwagandha (Withania somnifera) which is a unique and distinct than normal erect type. Indian J. Plant Gen. Res., 26(3): 260.

Mir, B.A., Khazir, J., Mir, N.A., Hasan, T., Koul, S. 2012. Botanical, chemical and pharmacological review of Withania somnifera (Indian ginseng): an ayurvedic medicinal plant. Indian J. Drugs Dis., 6: 2278-2958.

Mishra, L.C., Singh, B.B., Simon, D. 2000. Scientific basis for the therapeutic use of Withania somnifera (Ashwagandha): a review. Alternative Med. Rev., 5(4): 334346.

Misra, H.O., Sharma, J.R., Lal, R.K. 1998. Genetic divergence in ashwagandha (Withania somnifera). J. Med. Arom. Plants, 20: 1018-1021.

Mohammadi, S.A., Prasanna, B.M. 2003. Analysis of genetic diversity in crop plants-salient statistical tools and considerations. Crop Sci., 43: 1235-1248.

Murthy, B.R., Arunachalam, V. 1966. The nature of genetic divergence in relation to breeding system in crop plants. Indian J. Genet Plant Breed., 26: 188-189.
Patterson, H.D., Thompson, R. 1971. Recovery of inter-block information when block sizes are unequal. Biometrika, 58, 545-554.

Rao, C.R. 1952. Advanced statistical methods in biometrical research. Willey and sons, New York.

Sarkar, P., Vijay, N., Silawat, N., Garg, R.K., Chouhan, S., Batav, N., Sharma, R., Mehrotra, N.N. 2013. Inter-species association of opium genus as revealed through random amplified polymorphic DNA Fingerprinting. Sci. Secure $J$. Biotechnol., 1(1): 1-8.

SAS Institute. 2009. SAS software. SAS Institute INC., Cary. NC. USA.

Sharma, N.S., Lavie, S. 1981. Chemistry and genetics of withanolides in Withania somnifera hybrids. Phytochem., 20: 27412748

Sharma, A., Vats, S.K., Pati, P.K. 2014. Postinflectional dynamics of leaf spot disease in Withania somnifera. Ann. Appl. Biol., 165: 429-440.

Shinde, A., Pankaj, G., Kumar, R.S. 2015. Conservation and sustainability of Ashwagandha: A medicinal plant. Int. J. Biol. Sci., 3(2): 94-99.

Singh, S., Kumar, S. 1998. The Indian GinsengAshwagandha.Central Council for Research in Indian Medicine and Homeopathy, New Delhi.

Singh, R.K., Chaodhury, B.D. 1977. Biometrical methods in quantitative genetics analysis. Kalyani publishers, New Delhi.

Today, J.M. 1980. Effects of disruptive selection. III coupling and repulsion. Heredity, 14: 3539.

Yadav, O.P., Kumar, Y., Verma, P.K. 2008. Genetic diversity, association among metric traits and path co-efficient analysis in Ashwagandha (Withania somnifera). Haryana J. Hort., 38(1/2): 23-26.

\section{How to cite this article:}

Ponnuchamy Manivel, Rama Reddy Nagaraja Reddy and Harshal B. Deore. 2017. Genetic Diversity for Root Yield and its Component Traits in Ashwagandha (Withania somnifera (L) Dunal) Pure Lines Derived from JA134 Population. Int.J.Curr.Microbiol.App.Sci. 6(4): 16941710. doi: https://doi.org/10.20546/ijcmas.2017.604.203 
Supplementary Table.1 Analysis of variance (ANOVA) for 20 root yield and its component traits in ashwagandha pure lines

\begin{tabular}{|l|l|l|l|}
\hline Trait & Replication & Genotype & Error \\
\hline df & 2 & 49 & 98 \\
\hline Plant height (PH) & 17.2 & $373.00^{* *}$ & 13.09 \\
\hline Stem height (SH) & 2.59 & $78.51^{* *}$ & 4.53 \\
\hline Stem girth (SG) & 0.11 & $11.06^{* *}$ & 0.49 \\
\hline Primary branches (PB) & 0.31 & $17.02^{* *}$ & 0.79 \\
\hline Secondary branches (SB) & 0.25 & $47.07 * *$ & 2.73 \\
\hline $\begin{array}{l}\text { Primary Branch length } \\
\text { (PBL) }\end{array}$ & 6.36 & $242.72^{* *}$ & 19.45 \\
\hline $\begin{array}{l}\text { Secondary branch length } \\
\text { (SBL) }\end{array}$ & 1.53 & $105.24 * *$ & 4.87 \\
\hline Primary root length (RL) & 1.29 & $66.88^{* *}$ & 5.75 \\
\hline Root girth at top (RGT) & 1.29 & $61.86^{* *}$ & 1.48 \\
\hline $\begin{array}{l}\text { Root girth in the middle } \\
\text { RGM) }\end{array}$ & 0.29 & $40.66^{* *}$ & 0.82 \\
\hline Root girth at bottom (RGB) & 0.09 & $9.77^{* *}$ & 0.51 \\
\hline Secondary roots (SR) & 8.24 & $47.01 * *$ & 3.13 \\
\hline Secondary root length (SRL) & 7.33 & $36.99 * *$ & 3.28 \\
\hline Secondary root girth (SRG) & 2.08 & $8.91 * *$ & 0.64 \\
\hline Number of berries (NB) & 14368.53 & $44297.39 * *$ & 16212.9 \\
\hline Number of leaves (NL) & 2156.7 & $66767.46^{* *}$ & 3226.7 \\
\hline Leaf yield (LY) & 9.86 & $631.52^{* *}$ & 16.81 \\
\hline Stem yield (STY) & 43.8 & $1867.40^{* *}$ & 47.96 \\
\hline Root yield (RY) & 5.03 & $198.29 * *$ & 5.16 \\
\hline Seed yield (SY) & 114.01 & $1548.27 * *$ & 48.87 \\
\hline
\end{tabular}


Supplementary Figure.1 Distribution of 20 root yield and its component traits in ashwagandha pure lines
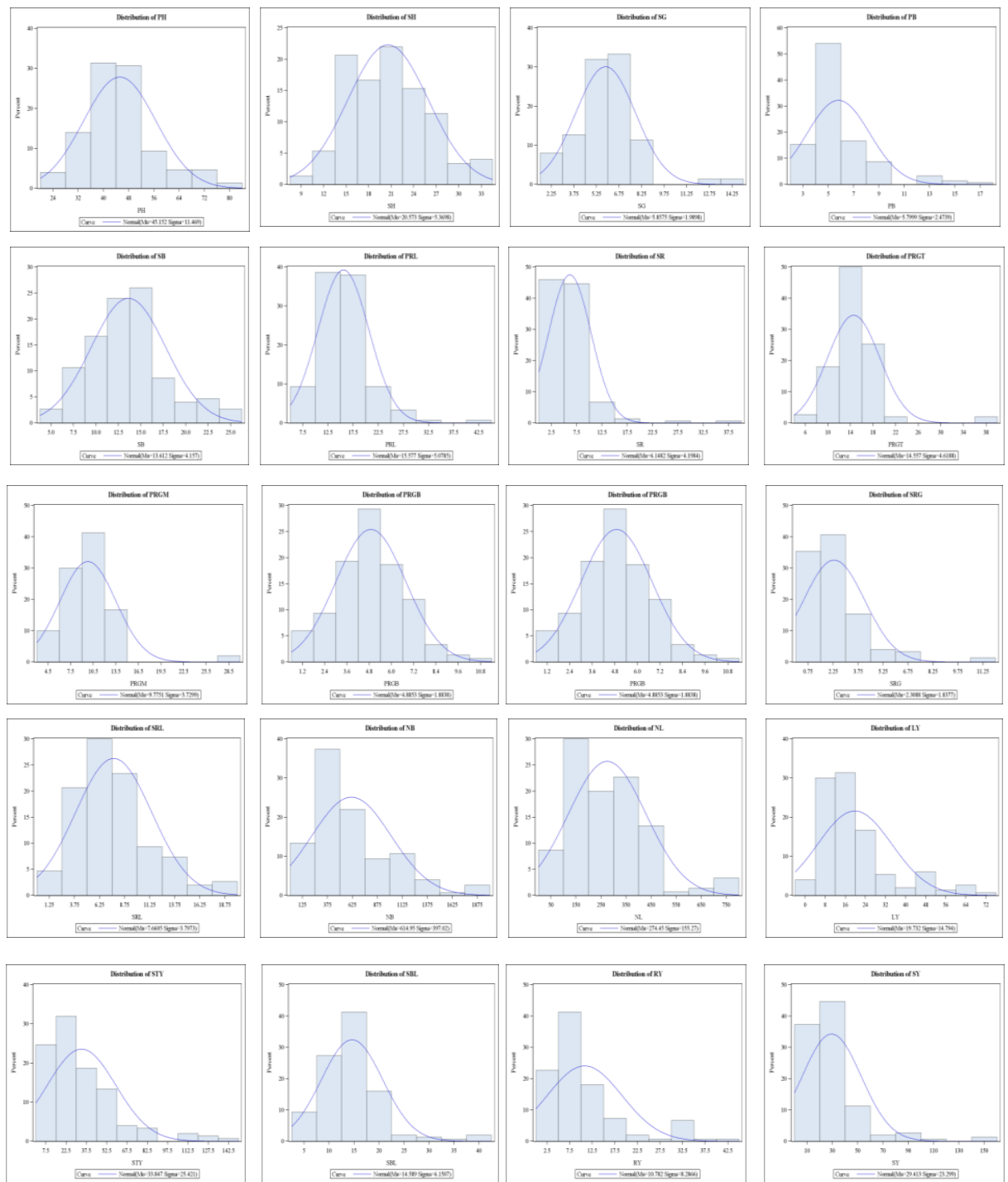